\title{
STEENBEEK FOOT ABDUCTION BRACE FOR CLUBFOOT: COST-EFFECTIVE BUT IS IT EFFECTIVE? A PROSPECTIVE STUDY
}

THATIKONDA SAI DINESH*, PREM KOTIAN, PREMJIT SUJIR, VARGHESE JOE, RAJENDRA A

Department of Orthopaedics, Kasturba Medical College, Mangalore, Karnataka, India. Email: thatikonda.diny@gmail.com

Received: 23 November 2016, Revised and Accepted: 07 February 2017

Objectives: To evaluate the effectiveness of Steenbeek FAB (SFAB) to maintain correction achieved and to study the reasons for failure and complications associated with the brace.

Methods: In Kasturba Medical College, Mangalore and allied hospitals between June 2014 and August 201625 patients (38 feet) who were treated by Ponseti method of cast application were given the SFAB and followed up for a minimum duration of 1 year. The status of the foot was assessed using Pirani score before brace application and at every follow-up. Compliance with the brace protocol was assessed and compliance defined as brace application for $23 \mathrm{hrs} /$ day for the first 3 months, and nap time brace application for rest of the duration of study.

Results: In 36 of 38 feet on the brace the correction was maintained ( $94.7 \%$ effective). In two patients (feet) there was worsening of the Pirani score after brace application and recurrence was seen. The reason for failure was found to be noncompliance. The correlation between noncompliance and recurrence was significant $(\mathrm{p}<0.001)$ using Fischer exact test. Pirani score improved significantly in a compliant group with significant worsening noted in noncompliant group. There were no other brace related complications.

Conclusions: The significant correlation between noncompliance and recurrence shows that SFAB is effective in maintaining correction and can be a cost-effective alternative to the more costly braces, for use in developing countries.

Keywords: Clubfoot, Congenital Talipes Equino Varus, Clubfoot braces.

(C) 2017 The Authors. Published by Innovare Academic Sciences Pvt Ltd. This is an open access article under the CC BY license (http://creativecommons. org/licenses/by/4. 0/) DOI: http://dx.doi.org/10.22159/ajpcr.2017.v10i5.16296

\section{INTRODUCTION}

Clubfoot if untreated can be very disabling, being the most common deformity of musculoskeletal system seen at birth reportedly occurring in about 1/1000 live births [1], if left untreated can be source of a huge economic burden especially in populous developing countries like India. The traditional method of surgery was proven to have dissatisfactory results producing a scarred painful stiff foot in many cases [2,3]. Ponseti described his method of serial casting for correcting the deformity using simple plaster casts [4], by this method clubfoot can be corrected in most cases in a very short time, but if left as it is after correction the deformity has a strong tendency to recur. A brace is required to prevent recurrence [4-8]. Ponseti has recommended what is termed as a foot abduction brace (FAB) to keep the corrected foot in $15^{\circ}$ dorsiflexion and $70^{\circ}$ abduction. In children with unilateral involvement the brace holds the normal foot in 450 abduction and 150 dorsiflexion [9]. Many braces are available which meet the required criteria. The effectiveness, ease of use and problems associated with most of the braces are largely unknown [10]. Some braces such as the Markell brace [7] and Mitchell-Ponseti brace [11] have been studied and are under use in most developed nations, however these braces are costly, costing 100-300 $\$$ and out of reach for most people in developing nations [10]. Steenbeek brace developed by Steenbeek and David in Uganda is one that meets the criteria and is easy to manufacture locally and is cost-effective [12]. Efficacy of this brace if definitively established and proven to be comparable to the other standard braces it can be a reliable alternative to the more costly braces for use in developing countries.

\section{Aim of the study}

To evaluate the effectiveness of Steenbeek FAB (SFAB) to prevent recurrence after clubfoot correction by casting method described by
Ponseti. To study the reasons for failure and complications associated with brace use.

\section{METHODS}

Among the children diagnosed with clubfoot who were treated at Kasturba Medical College, Mangalore, and its allied hospitals between June 2014 and August 2016, ones under 1 year of age with idiopathic clubfoot were selected for the study and those with any other associated neurological conditions or lower limb disorders or those who had undergone previous treatment were excluded, this came to a sample size of 25 patients (38 feet). The caretakers of these children were explained about the study its nature and purpose and their consent taken before inclusion into the study. The permission to conduct this prospective study was obtained from the Institutional Ethics Committee. At the start, children were examined and the demographic data obtained and the Pirani score [13] was assessed before the start of the treatment and the data recorded. The feet were then corrected by weekly casts by the method described by Ponseti [4], and the Pirani score was assessed and recorded after each cast and percutaneous tenotomy was done in outpatient setup if indicated by the lack of at least $10^{\circ}$ of dorsiflexion when $60-70^{\circ}$ of abduction was achieved and feet put in cast for 3 weeks. After completing, the casting phase the Pirani score was recorded, and SFAB was applied which held the feet in $70^{\circ}$ of abduction and $15^{\circ}$ dorsiflexion with the feet separated by a bar equal to the shoulder breadth. In unilateral involvement, the normal foot was kept at $45^{\circ}$ abduction and $15^{\circ}$ dorsiflexion. The caretakers were instructed on the importance of the brace and taught how to apply the brace and were made to apply the brace under supervision to check if it was properly done, the doctors were also available for contact on phone at all times to answer any queries they may have or needed any advice regarding problems with the brace. They were advised to keep 
the brace on for at least 23 hrs each day for the first 3 months and later at night and whenever the child sleeps for the rest of the duration of the study. If they were applying the brace correctly and for the prescribed duration, they were taken as being compliant with the brace. They were followed up intervals of 3 weeks, 8 weeks, 3 months, 6 months, 9 months, and 1 year from brace application and every 3 months for the rest of study duration. At each visit, the Pirani score was assessed and recorded and the feet were checked for any recurrence or local complications due to brace use. The caretakers were interviewed to know if they encountered any problems while using the brace and to ascertain that it was applied for the prescribed duration. At each visit, caretakers were made to apply the brace under supervision to check if it was done correctly.

\section{RESULTS}

We were able to follow-up 25 patients ( 38 feet) for a minimum of 1 year on the brace with mean follow-up of 21 months (range 12-24 months) of which there were 7 girls (28\%), and 13 children (52\%) had bilateral affection. The mean age of starting treatment was 15.8 weeks (standard deviation 14.06). Of the 12 unilateral cases, right foot affection was more common ( 9 feet - 75\%). Tenotomy was performed for 31/38 (81.6\%) feet. The mean Pirani score at the start of treatment was 3.79, during the start of bracing was 0.65 . Recurrence was seen in 2 cases ( 2 feet). In $1^{\text {st }}$ case recurrence was noted in the $6^{\text {th }}$ month after brace application, in $2^{\text {nd }}$ case it was after 1 year. In both cases, it was found that the brace was not applied for the prescribed duration each day and sometimes for few days at a stretch. These children were categorized as noncompliant with the brace. There was full compliance with all the other children and no recurrence was seen. From this, the rate of compliance comes to $94.7 \%$ and rate of recurrence was $5.3 \%$ in the $1^{\text {st }}$ year with brace. In the 2 cases with recurrence recasting was done and later put on brace and the caretakers were again counseled about the importance of the brace. Till the end of study period, there was no recurrence noted in these feet and they remained compliant with the brace. The correlation between noncompliance and recurrence was analyzed for statistical significance using Fisher exact test which showed a highly significant correlation $(\mathrm{p}<0.001)$ (Table 1$)$

The change in Pirani score form the time of brace application to last follow-up/recurrence was assessed in the compliant group there was a median decrease in score by 0.5 , and in the noncompliant group, there was a median increase of 0.75 . When the change was compared between the two groups Mann-Whitney test $\mathrm{Z}$ value was 3.72 and $\mathrm{p}<0.001$ (Table 2).

Among the two groups of patients which are those with recurrence and those without recurrence, the comparison was made between the Pirani scores at the time of starting treatment (manipulation and casting), at the time of brace application and at the end of 1 year or at time when recurrence was noted. The Pirani scores at the start of treatment and at brace application showed no significant difference with the MannWhitney test, but the scores between the two groups at the end were significantly different with $\mathrm{p}<0.001$ (Table 3 ).

The recurrence and no recurrence groups were also compared in relation to difference in the age at which treatment was started, the number of casts needed to correct and the need for tenotomy all of which showed no statistically significant differences between the recurrence and no recurrence groups. In our study, there were no brace related local complications such as abrasions, sores or ulcers.

\section{DISCUSSION}

Due to the poor results of surgical treatment most orthopedic surgeons now agree that clubfoot must initially be treated by serial casts. Technique described by Ponseti has shown best short and long term results and is the currently recommended method. Studies by Ponseti and others in various centers show that almost all idiopathic clubfeet can be corrected by this method, with about $80 \%$ requiring a
Table 1: Comparision of relation of Compliance and Recurrence

\begin{tabular}{llll}
\hline Compliance & \multicolumn{2}{l}{ Recurrence } & \\
\cline { 2 - 4 } & Yes & No & Total (\%) \\
\hline Yes & 0 & 36 & $36(94.7)$ \\
No & 2 & 0 & $2(5.3)$ \\
Total (\%) & $2(5.3)$ & $36(94.7)$ & $38(100)$ \\
\hline
\end{tabular}

Fisher exact test: $\mathrm{p}=0.001 \mathrm{HS}$

Table 2: Score change from brace application to end/recurrence

$\begin{array}{llllll}\text { Compliance } & \begin{array}{l}\text { Mean } \\ \text { change }\end{array} & \begin{array}{l}\text { SD } \\ \text { change }\end{array} & \begin{array}{l}\text { Median } \\ \text { change }\end{array} & \begin{array}{l}\text { Mann-Whitney } \\ \text { test Z value }\end{array} & \text { p value } \\ \text { No } & -0.75 & 1.768 & -0.75 & 3.72 & <0.001 \\ \text { Yes } & 0.625 & 0.42 & 0.5 & & \end{array}$.

SD: Standard deviation

Table 3: Scores at various stages between Recurrence and Nonrecurrence groups

\begin{tabular}{lllll}
\hline $\begin{array}{l}\text { Scoring } \\
\text { stages }\end{array}$ & Recurrence & $\mathbf{N}$ & Mean \pm SD & $\begin{array}{l}\text { Mann-Whitney } \\
\text { test }\end{array}$ \\
\hline $\begin{array}{l}\text { Score before } \\
\text { presentation }\end{array}$ & Yos & 2 & $3.0 \pm 0.7071$ & $\mathrm{Z}=0.653$, \\
$\begin{array}{l}\text { Score at end/ } \\
\text { recurrence }\end{array}$ & No & 36 & $3.833 \pm 1.7768$ & $\mathrm{p}=0.518, \mathrm{NS}$ \\
\hline
\end{tabular}

SD: Standard deviation

tenotomy. Although most cases correction is possible high recurrence rate $(56 \%)[3,4,8,14,15]$ was reported initially. Most studies currently report a recurrence rate of $30-45 \%[6,14,16-19]$. Hence, to maintain correction and reduce risk of recurrence the application of an FAB is recommended. FAB must be applied continuously ( $23 \mathrm{hrs}$ ) for first 3 months and at nap time till child is 4-5 years.

The Markell brace and Mitchell Ponseti brace are the most widely used braces in developed countries. The experience with Markell brace was reported by M. Thacker et al. in 2005 on 30 patients (44 feet), where they found $18 \%$ noncompliance with the brace of which $57 \%$ ( 8 feet) showed recurrence with no recurrence in those compliant with brace and concluded that brace was essential to prevent recurrence [7]. Mitchell Ponseti brace described for complex clubfeet was studied on 84 feet (57 patients) with idiopathic clubfoot and reported by L. Zionts et al. in 2012 who found 40\% noncompliance with 48\% recurrence rate of which $30 \%$ were noncompliant, in $18 \%$ feet recurrence was seen in spite of being adherent to the brace [11]. Although these braces were found effective and are widely used in the developed countries, they are costly (100-300\$) and hence out of reach for most of the people in developing countries.

Recurrence for deformity can still occur even with FAB use, and various factors have been studied as possible factors influencing recurrence. Factors such as initial disease severity, age of starting treatment, previous treatment, total casts required, tenotomy, gender, family history of clubfoot, and social status, which were suggested as possible influences were shown have no influence on recurrence [8,15,17-21].

Compliance with brace has been identified as the most important factor influencing recurrence [5,4,7,14,18,19,21-26]. Morcuende et al. reported in a study that noncompliant group had an $80 \%$ recurrence when compared to only $6 \%$ recurrence in compliant group. To improve compliance costlier braces with modifications like Kessler's brace [23] and dynamic FAB $[6,27]$ have been described, studies on Kessler's brace and the dynamic brace showed higher compliance, but the reported increase in compliance is not definitively proven to be a consequence of brace modification. It is now increasingly noted that educating the 
parents about the recurring nature of the disease and importance of brace in preventing recurrence and establishing channels of communication with parents to solve problems encountered in the daily use of brace has a larger role in improving compliance [24]

The problem in developing countries is that braces are not readily available and even if made available their cost makes them out of reach for most people. Steenbeek brace (SFAB) described by Mitchel Steenbeek can be made from locally available materials at very low cost $(10 \$)$, and the templates for its manufacture are freely available over the internet [12]. A study by Bouchoucha et al. in 2008 reported a compliance rate of $94 \%$ with SFAB among 66 patients (95 feet) with recurrence in 5 patients $(9$ feet $=7.5 \%) 4$ of them were noncompliant [28].

In our study after a mean follow-up of 21 months with SFAB $94.7 \%$ were compliant, recurrence occurred in 2 feet/patients (5.3\%) both of whom were noncompliant with brace use. We found that brace compliance was the only major factor influencing recurrence. In all cases, the parents were educated about the disease and importance of brace, at every visit parents were made to apply brace under supervision and encouraged to immediately contact us if they encountered any problems. This could be the reason for the good compliance noted in our study.

The SFAB is easy to obtain and maintain and is affordable by most people in developing countries. As a child grows they generally need 2-3 brace size changes in an year and the brace maintains its functional integrity for much longer duration and any minor wear and tear can be repaired easily to retain function, hence if it can be used at an institute like ours which is a referral center for district with staff specifically assigned for clubfoot management, and resources to store and repair the brace and where patients can be expected to be in constant touch with the institute the brace can be reused for another child after one grows out of the brace, this further reduces the per capita cost of the brace.

Other studies on different braces reported complications such as abrasions and ulcers in 4-14\% cases [29], however, there were no local complications in any patients in our study.

Our study had the limitation of a shorter duration of follow-up with mean of 21 months and the minimum being 1 year, and the sample size was 25 children ( 38 feet). Furthermore, we found a strong association $(p<0.001)$ between recurrence and inadequate brace use with worsening of Pirani score. In those who used the brace correctly, the feet maintained correction and even showed improvement in Pirani score. And its efficacy and compliance $(94.7 \%)$ was found to be comparable to other more costly braces.

\section{CONCLUSION}

It can be said that SFAB application with appropriate parent education is a good and cost-effective means of preventing recurrence in Ponseti method of clubfoot, especially in developing countries.

\section{REFERENCES}

1. Pirani S, Naddumba E. Ponseti Clubfoot Management: Teaching Manual for Health-Care Providers in Uganda: Global-help Organization; 2008. Available from: http://www.global-help.org/publications/books/help_ ponsetiuganda.pdf. [Last cited on $2016 \mathrm{Jul} 26$ ]

2. Dobbs MB, Morcuende JA, Gurnett CA, Ponseti IV. Treatment of idiopathic clubfoot: An historical review. Iowa Orthop J 2000;20:59-64.

3. Ponseti IV. Treatment of congenital club foot. J Bone Joint Surg Am 1992;74(3):448-54.

4. Ponseti IV, Smoley EN. The classic: Congenital club foot: The results of treatment 1963. Clin Orthop Relat Res 2009:467(5):1133-45.

5. Boehm S, Sinclair M. Foot abduction brace in the Ponseti method for idiopathic clubfoot deformity: Torsional deformities and compliance. J Pediatr Orthop 2007;27(6):712-6.

6. Chen RC, Gordon JE, Luhmann SJ, Schoenecker PL, Dobbs MB A new dynamic foot abduction orthosis for clubfoot treatment. J Pediatr Orthop 2007;27(5):522-8.

7. Thacker MM, Scher DM, Sala DA, van Bosse HJ, Feldman DS, Lehman WB. Use of the foot abduction orthosis following Ponseti casts: Is it essential? J Pediatr Orthop 2005;25(2):225-8

8. Morcuende JA, Dolan LA, Dietz FR, Ponseti IV. Radical reduction in the rate of extensive corrective surgery for clubfoot using the Ponseti method. Pediatrics 2004;113(2):376-80.

9. Kumar SJ. Congenital Clubfoot. Fundamentals of treatment. Ignacio V. Ponseti. New York, Oxford University Press, 1996. J Bone Joint Surg Am 1997;79(3):477.

10. Desai L, Oprescu F, DiMeo A, Morcuende JA. Bracing in the treatment of children with clubfoot: Past, present, and future. Iowa Orthop J 2010;30:15-23.

11. Zionts LE, Frost N, Kim R, Ebramzadeh E, Sangiorgio SN. Treatment of idiopathic clubfoot: Experience with the Mitchell-Ponseti brace. J Pediatr Orthop 2012;32(7):706-13.

12. Steenbeek HM, David OC. Steenbeek Brace for Clubfoot. $2^{\text {nd }}$ ed. Production Manual for the Steenbeek Foot Abduction Brace SFAB; 2009. Available from: https://www.global-help.org/publications/books/ help_steenbeekbrace.pdf.

13. Catterall A. A method of assessment of the clubfoot deformity. Clin Orthop Relat Res 1991;48-53.

14. Ramírez N, Flynn JM, Fernández S, Seda W, Macchiavelli RE. Orthosis noncompliance after the Ponseti method for the treatment of idiopathic clubfeet: A relevant problem that needs reevaluation. J Pediatr Orthop 2011;31(6):710-5

15. Ponseti IV, Campos J. The classic: Observations on pathogenesis and treatment of congenital clubfoot 1972. Clin Orthop Relat Res 2009;467(5):1124-32.

16. Elshenawy EM, Hassanen EY, Ramadam AI, Ibrahim MM. The Mansoura experience in the treatment of idiopathic clubfoot deformity using the Ponseti technique. Acta Orthop Belg 2008;74(5):659-66.

17. Bor N, Coplan JA, Herzenberg JE. Ponseti treatment for idiopathic clubfoot: Minimum 5-year followup. Clin Orthop Relat Res 2009:467(5):1263-70.

18. Avilucea FR, Szalay EA, Bosch PP, Sweet KR, Schwend RM. Effect of cultural factors on outcome of Ponseti treatment of clubfeet in rural America. J Bone Joint Surg Am 2009;91(3):530-40.

19. Dobbs MB, Rudzki JR, Purcell DB, Walton T, Porter KR, Gurnett CA. Factors predictive of outcome after use of the Ponseti method for the treatment of idiopathic clubfeet. J Bone Joint Surg Am 2004;86$\mathrm{A}(1): 22-7$

20. Alves C, Escalda C, Fernandes P, Tavares D, Neves MC. Ponseti method: Does age at the beginning of treatment make a difference? Clin Orthop Relat Res 2009;467(5):1271-7.

21. Willis RB, Al-Hunaishel M, Guerra L, Kontio K. What proportion of patients need extensive surgery after failure of the Ponseti technique for clubfoot? Clin Orthop Relat Res 2009:467(5):1294-7.

22. Haft GF, Walker CG, Crawford HA. Early clubfoot recurrence after use of the Ponseti method in a New Zealand population. J Bone Joint Surg Am 2007;89(3):487-93.

23. Kessler JI. A new flexible brace used in the Ponseti treatment of talipes equinovarus. J Pediatr Orthop B 2008;17(5):247-50

24. Zionts LE, Dietz FR. Bracing following correction of idiopathic clubfoot using the Ponseti method. J Am Acad Orthop Surg 2010;18(8):486-93.

25. George HL, Unnikrishnan PN, Garg NK, Sampath J, Bruce CE. Unilateral foot abduction orthosis: Is it a substitute for Denis Browne boots following Ponseti technique? J Pediatr Orthop B 2011;20(1):22-5.

26. Dobbs MB, Gurnett CA. Update on clubfoot: Etiology and treatment. Clin Orthop Relat Res 2009:467(5):1146-53.

27. Garg S, Porter K. Improved bracing compliance in children with clubfeet using a dynamic orthosis. J Child Orthop 2009;3(4):271-6.

28. Bouchoucha S, Smida M, Saïed W, Safi H, Ammar C, Nessib MN, et al. Early results of the Ponseti method using the Steenbek foot abduction brace: A prospective study of 95 feet. J Pediatr Orthop B 2008;17(3):134-8 
29. Mang'oli P, Theuri J, Kollmann T, MacDonald NE. Ponseti clubfoot management: Experience with the Steenbeek foot abduction brace. Paediatr Child Health 2014;19(10):513-4. 